\title{
Investigation of the effect of benzothiazinesulfonamide derivatives as inhibitors of microbiological corrosion of steel with composite zinc/biocide coating
}

\author{
Angela Gribankova ${ }^{1, *}$, Maria Agievich ${ }^{1}$, Xiaofan Zhai ${ }^{2,3,4}$, Jizhou Duan ${ }^{2,3,4}$, Baorong Hou $^{2,3,4}$ \\ ${ }^{1}$ Immanuel Kant Baltic Federal University, 236018 Kaliningrad, Russia \\ ${ }^{2}$ CAS Key Laboratory of Marine Environmental Corrosion and Bio-fouling, Institute of Oceanology, Chinese Academy of Sciences, \\ 266071 Qingdao, PR China \\ ${ }^{3}$ Open Studio for Marine Corrosion and Protection, Pilot National Laboratory for Marine Science and Technology (Qingdao), 266235 \\ Qingdao, PR China \\ ${ }^{4}$ Center for Ocean Mega-Science, Chinese Academy of Sciences, Qingdao, PR China
}

\begin{abstract}
This study evaluated the biocidal and electrochemical inhibitory effectiveness of the organic compound (OC) 1,2,3,4,4a, 10b-hexahydro-1,4-methano-6H-dibenzo [c, e] -5,6-thiazine-5,5-dioxide when introduced into a zinc-plating electrolyte. Structural and metallurgical analysis of the resultant coatings was carried out using XRD and SEM techniques. During zinc electrodeposition, OC molecules were adsorbed on the surface of the zinc coatings. In a corrosive medium, destruction of molecules in the crystal lattice surface stopped the sulphate-reducing bacterial metabolic chain and retarded the corrosion process. The coatings exhibited high corrosion-resistance and good physical characteristics.
\end{abstract}

\section{Introduction}

Protecting metals from microbiological corrosion in seawater is a matter of acute current interest, since corrosion processes lead to the loss of considerable amounts of metals as well as damage to ships, devices and equipment in marine and coastal environments. Solving this problem would prolong the service life of high-value constructions and protect metals and alloys [1]. Zinc coatings are used extensively for the protection of mild steel in various corrosive media. Zinc coatings have attracted much attention because they possess higher corrosion-resistance and better mechanical characteristics than other metal coatings. Galvanised steel is frequently used in the construction of cooling towers, water containers and structures for housing animals, among others, owing to its good corrosion resistance, mechanical workability and resistance to biofouling [2]. The corrosion resistance of this metal has been attributed to the formation of a protective layer of $\mathrm{Zn}(\mathrm{OH})_{2}[3]$.

Soil and natural water are harmful to metals because of corrosion-accelerating metabolic substances produced by certain microorganisms, including bacteria. In natural and artificial media with very limited air or none at all, microbiologically induced corrosion can occur primarily because of the activity of anaerobic microbial populations. Among such microbes, sulphate-reducing bacteria (SRB) seem to have the most pronounced corrosion-stimulating action. SRB have been isolated from a variety of environments - soil, seawater, fresh- water, fuel tanks, paper mills, heat-exchange closed water systems and water treatment tanks $[4,5]$. These heterotrophic microorganisms play a major role in anaerobic bio-corrosion and generate corrosion-active metabolites (e.g., $\mathrm{H}_{2} \mathrm{~S}, \mathrm{NH}_{3}, \mathrm{CO}_{2}$ and carboxylic acids). They also cause damage to oil and oil products.

These bacteria affect gas and oil pipelines, the heatexchange circuits of internal combustion engines, drilling rigs, equipment for oil and gas refining, and metal containers. Microbial biofilm formation and corrosion in these systems are the most common problems that damage valuable equipment, cause loss of production and increase maintenance costs. Numerous studies have demonstrated microbiologically influenced corrosion of a number of metals under laboratory and in situ conditions [6-11]. Desulfovibrio is usually the predominant genus in mixed cultures of SRB [12]. The present study is based on research using a pure culture of Desulfovibrio desulfuricans and a standard Postgate C medium to ensure the reproducibility of the results and allow a clear accounting for all experimental observations.

\section{Materials and methods}

Four sets of experiments were carried out - three to test the effectiveness of the organic compound (OC) 1,2,3,4,4a, 10b-hexahydro-1,4-methano-6H-dibenzo [c, e] -5,6-thiazine-5,5-dioxide when introduced into a zincplating electrolyte, each having different characteristics,

\footnotetext{
*Corresponding author: agribankova@mail.ru
} 
and a fourth control group. Each experiment involved three samples prepared under the same conditions.

\subsection{Metallic coatings}

Galvanised coatings were deposited on steel sheets with the following chemical composition: C, $0.17 \%-0.24 \%$; Si, $0.17 \%-0.37 \%$; Mn, 0.35\%-0.65\%; P $\leq 0.040 \%$; $\mathrm{S} \leq$ $0.045 \%$. Maintaining low levels of $\mathrm{Si}$ and $\mathrm{P}$ is crucial because these elements can strongly affect the microstructure and thickness of the metal layer, producing metallic coatings with low performance [3]. Samples (size, $\sim 50 \times 13 \mathrm{~mm}$; thickness, $2 \mathrm{~mm}$ ) were polished with a series of emery papers of different grit sizes (successively on each sample 400, 600, 800, 1200 and 2000). Next, the samples were cleaned with ethanol and double-distilled water and then dried in air under laboratory conditions. Prior to any experiment, the substrates were treated as described and then used immediately with no further storage. The zinc coatings were deposited from an electrolyte containing $250 \mathrm{~g} / \mathrm{L}$ $\mathrm{ZnSO}_{4} \cdot 7 \mathrm{H}_{2} \mathrm{O}, 80 \mathrm{~g} / \mathrm{L} \quad \mathrm{Na}_{2} \mathrm{SO}_{4}, 25 \mathrm{~g} / \mathrm{L} \mathrm{H}_{3} \mathrm{BO}_{3}, 20 \mathrm{~g} / \mathrm{L}$ $\mathrm{Al}\left(\mathrm{SO}_{4}\right)_{3} \cdot 18 \mathrm{H}_{2} \mathrm{O}$ and $1 \mathrm{~g} / \mathrm{L}$ gelatin. The $\mathrm{pH}$ level of the electrolyte bath was 3.84. An environmentally friendly organic compound (OC) at concentrations of 1,2 and 5 (Table1) was used as an additive for the electrolyte. The $\mathrm{N}$ - and S-containing OC not only successfully inhibited microbial corrosion and steel hydrogenation but also showed inhibitory and bactericidal properties with respect to actively corrosive microorganisms, demonstrating a high protective effect.

The thickness of the $\mathrm{Zn}$ coatings was $30 \mu \mathrm{m}$ and was controlled by monitoring the amount of charge passing for deposition under different current densities (50, 100, 150 and $200 \mathrm{~A} / \mathrm{m}^{2}$ ).

The surface morphologies of the coatings were analysed using IR (Thermo Scientific Nicolet in 10), SEM and EDS (JEOL JSM-6700F). The phase composition and preferred orientation of the coatings were evaluated by XRD (D8 ADVANCE; Bruker).

Captions should be typed in 9-point Times. They should be centred above the tables and flush left beneath the figures.

\subsection{Microbiological tests}

D. desulfuricans stamps were separated from a natural source and cultivated as a pure culture in Postgate $\mathrm{C}$ medium at the Immanuel Kant Baltic Federal University. The basal medium was composed of $0.25 \mathrm{~g} / \mathrm{L} \mathrm{KH}_{2} \mathrm{PO}_{4}$, $0.5 \mathrm{~g} / \mathrm{L} \quad \mathrm{NH}_{4} \mathrm{Cl}, \quad 0.03 \mathrm{~g} / \mathrm{L} \quad \mathrm{CaCl}_{2} \cdot 6 \mathrm{H}_{2} \mathrm{O}, \quad 0.03 \mathrm{~g} / \mathrm{L}$ $\mathrm{MgSO}_{4} \cdot 7 \mathrm{H}_{2} \mathrm{O}, \quad 0.15 \mathrm{~g} / \mathrm{L} \quad$ trisodium citrate $\left(\mathrm{C}_{6} \mathrm{H}_{5} \mathrm{Na}_{3} \mathrm{O}_{7} \cdot 2 \mathrm{H}_{2} \mathrm{O}\right), 0.5 \mathrm{~g} / \mathrm{L}$ yeast extract and $3 \mathrm{~g} / \mathrm{L}$ sodium DL-lactate $\left(\mathrm{C}_{3} \mathrm{H}_{5} \mathrm{O}_{3} \mathrm{Na}\right)$.

The experiments were carried out for nine days using $45 \mathrm{ml}$ glass tubes with rubber stoppers. Contact with iron is good for bacterial development; therefore, flat samples of steel measuring $50 \times 13 \times 2 \mathrm{~mm}$ were placed in test tubes sterilised at $120^{\circ} \mathrm{C}$ for 30 minutes with $35 \mathrm{ml}$ of Postgate $\mathrm{C}$ medium and $10 \mathrm{ml}$ of pure culture. Before being added to the medium, the samples were sanded with thin web sandpaper, degreased with ethanol and irradiated in a UV box (AIR TECH) for 20 minutes on each side. The test tubes were sealed with butyl-rubber septa and incubated at $30^{\circ} \mathrm{C}$. On the second day of the experiment, the primary samples were replaced with zinc-plated steel samples in different modes. Before irradiation, they were weighed on an electron scale accurate within $0.0001 \mathrm{~g}$.

The biocidal effects of the $\mathrm{OC}$ in an aqueous medium salted with metallic salts from the earlier phase of the experiment and with SRB, were measured, including the number of SRB cells, $\mathrm{pH}$ and redox potential, the electrode potential of mild steel, $\mathrm{S}^{2-}$ content and mass loss (corrosion rate (CR)) using standard microbiological tests. These results were compared against the control experiment results. The number of sulphur-reducing cells was counted under an OLYMPUS BX 25 microscope to determine the bacterial titre, with its reduction potentially indicating the biocidal action of the OC. The total number of bacteria per unit volume of the corrosive medium was determined using the following formula: Equations should be centred and should be numbered with the number on the right-hand side.

$$
M=\alpha \times 1000 / n \times S,
$$

where $\alpha$ is the average number of cells per square chamber,

$n$ is the depth of the chamber $(0.1 \mathrm{~mm})$ and

$S$ is the area of the square grid used in the eyepiece magnification $\left(1 / 400 \mathrm{~mm}^{2}\right)$.

The redox potential (with Pt electrode) and corrosive medium $\mathrm{pH}$ (with glass electrode) were measured daily on a universal pHS-3C. The electrode potential of the zinc-plated samples was measured daily with an electronic voltmeter (CH1760c). After seven days, the samples were removed from the corrosive medium, cleansed of corrosion products with a hard polymer brush and then weighed. The CR was measured gravimetrically from simultaneous experiments on three samples:

$$
K=(m 1-m 2) / S \times \tau,
$$

where $K$ is the $\mathrm{CR}\left(\mathrm{kg} / \mathrm{m}^{2} \cdot\right.$ day), $m_{l}$ is the initial sample mass $(\mathrm{kg})$, $m_{2}$ is the sample mass after tests $(\mathrm{kg})$, $S$ is the sample area $\left(\mathrm{m}^{2}\right)$ and $\tau$ is the time of deposition (day).

\section{Results and discussion}

Addition of an $\mathrm{OC}$ to the electrolyte for $\mathrm{Zn}$ electrodeposition increases the cathodic polarisation, indicating the adsorption mechanism of its action on the cathode surface. Densely packed adsorbed layers of OC molecules hinder access to the metal surface of the hydrated ions $\mathrm{H}_{3} \mathrm{O}^{+}$and $\mathrm{Zn}^{2+}$, and the volume of output of $\mathrm{Zn}$ is enhanced by the great difficulty of discharging hydroxonium ions. In the electrolyte without any additives, the potential slightly increased during the first 55 minutes, reaching a stable value. The OC at this stage 
of electrolysis caused a significant increase in the capacity of the cathode, which is a consequence of both the adsorption of molecules of different additives on the surface of the steel cathode and a cathode-forming coating, and the 'permeability' of the layer formed by discharging ions $\mathrm{Zn}^{2+}$ and $\mathrm{H}_{3} \mathrm{O}^{+}$. The current density of $50 \mathrm{~A} / \mathrm{m}^{2}$ showed that an increase in the concentration of additives in the electrolyte led to an increase in the polarisation of the cathode. However, 100, 150 and 200 $\mathrm{A} / \mathrm{m}^{2}$ exhibited less cathodic polarisation compared with $50 \mathrm{~A} / \mathrm{m}^{2}$, indicating partial desorption of the OC molecules from the cathode surface, resulting in increased base metal hydrogenation compared with the results obtained at lower current density. Good adsorption capacity of the OC is clearly related to the presence of atoms of S-, $\mathrm{N}$ - and $\mathrm{O}$ - that increase the adsorption of these molecules on a steel cathode.

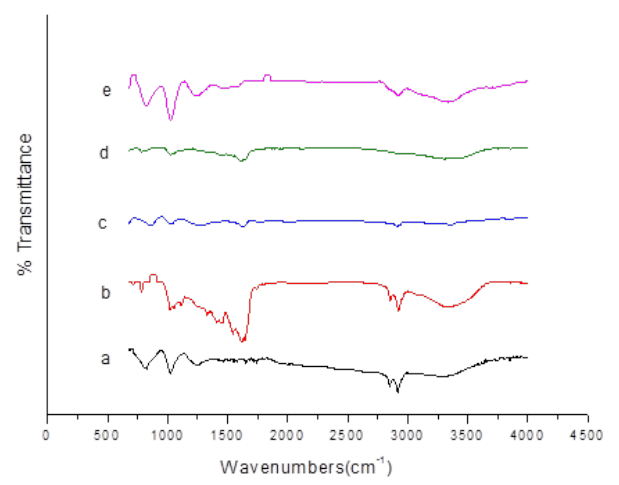

Fig. 1. IR test of samples (a) deposited from electrolyte without OC, (b) deposited (current density, $50 \mathrm{~A} / \mathrm{m}^{2}$ ) from electrolyte with $1 \mathrm{mmol} / \mathrm{L}$ OC, (c) deposited (current density, $50 \mathrm{~A} / \mathrm{m}^{2}$ ) from electrolyte with $2 \mathrm{mmol} / \mathrm{L}$ OC, (d) deposited (current density, $50 \mathrm{~A} / \mathrm{m}^{2}$ ) from electrolyte with $5 \mathrm{mmol} / \mathrm{L}$ OC and (e) deposited (current density, $100 \mathrm{~A} / \mathrm{m}^{2}$ ) from electrolyte with $2 \mathrm{mmol} / \mathrm{L} \mathrm{OC}$.

IR analyses revealed the structure of the OC on the surface of the $\mathrm{Zn}$ coating (Fig. 1). The protective properties of the OC are associated with the formation of multilayer films on the metal surface due to the coordination of covalent bonds between the substituent groups and the zinc atoms. IR testing also revealed the structures of the 1 and $5 \mathrm{mmol} / \mathrm{L}$ OCs obtained from the electrolyte bath on the surface of samples (current density, $50 \mathrm{~A} / \mathrm{m}^{2}$ ) (Fig. $1 \mathrm{~b}$ and $1 \mathrm{~d}$ ); however, the traces of the $\mathrm{OC}$ at the concentration of $2 \mathrm{mmol} / \mathrm{L}$ in the electrolyte for $\mathrm{Zn}$ deposition (current density, $50 \mathrm{~A} / \mathrm{m}^{2}$ ) were not clear (Fig. 1c). In addition, an analysis of $\mathrm{Zn}$ coatings (at current densities of 100, 150 and $200 \mathrm{~A} / \mathrm{m}^{2}$ ) demonstrated very weak traces of the OC on the surface.

At a current density of $200 \mathrm{~A} / \mathrm{m}^{2}$, the cathode potential demonstrated smaller values as reflected in the formation of low-quality deposits: a macro-crystalline precipitate formed, and this was accompanied by significant hydrogen absorption of steel substrates. Such a coating would have a weak protective effect on SRB and other microorganisms.
Addition of the $\mathrm{OC}$ in the electrolyte for $\mathrm{Zn}$ deposition strongly influenced the crystal growth mechanism (Fig. 2) and surface morphology. The results of X-ray diffraction measurements showed that $\mathrm{Zn}$ coatings deposited from the electrolyte without the OC had preferential growth along the (100), (101) and (110) orientations. When the concentration of the OC increased, the (002) diffraction peak became progressively more dominant; at a concentration of 2 $\mathrm{mmol} / \mathrm{L}$, the coatings were strongly textured with preferential orientation along the (002) axis. The same tendency was observed for the (101) direction. The higher chemical purity of the coatings accounted for the preferred orientation in the (002) direction of the electrodeposited coatings.
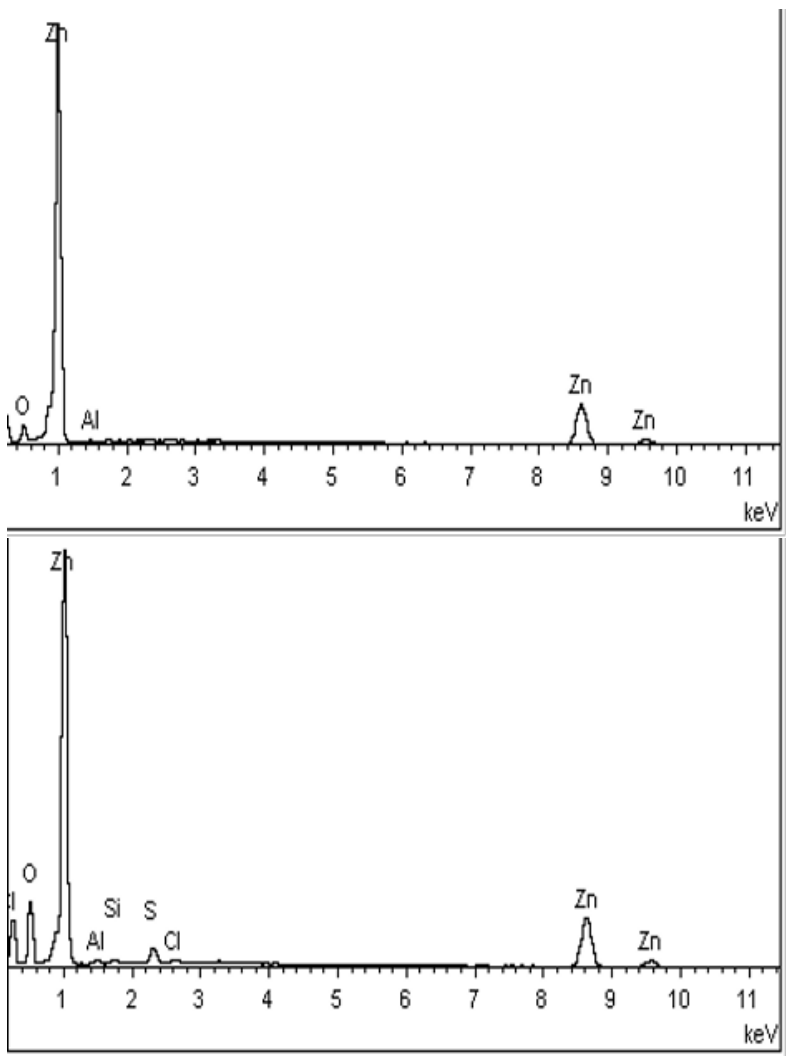

Fig. 2. X-ray diffractograms of $\mathrm{Zn}$ coatings (current density, $50 \mathrm{~A} / \mathrm{m}^{2}$ ) deposited from electrolytes (a) without OC, (b) with $1 \mathrm{mmol} / \mathrm{L}$ and (c) with $2 \mathrm{mmol} / \mathrm{L}$ OC.

Analysis of the experimental data demonstrated that CR slowed down after the steel samples were embedded with zinc electrodeposits and enriched with the OC while being deposited from the sulphide-acid electrolyte. The effectiveness of corrosion retardation decreased with decreasing OC concentration in the electrolyte (Fig.3). After eight days of exposure, a protective film of molecules formed on the surface of the zinc coatings. The OC and products of hydrogen sulphide corrosion of zinc, which were removed before weighing samples, were then evaluated.

1,2,3,4,4a, 10b-hexahydro-1,4-methano-6H-dibenzo [c, e] -5,6-thiazine-5,5-dioxide embedded in a zincplating electrolyte at concentrations ranging from 2 to 5 $\mathrm{mmol} / \mathrm{L}$ during deposition and at the current density of 
$50 \mathrm{~A} / \mathrm{m}^{2}$ demonstrated the most effective retardation of the CR (more than 33 times greater than with the control series).

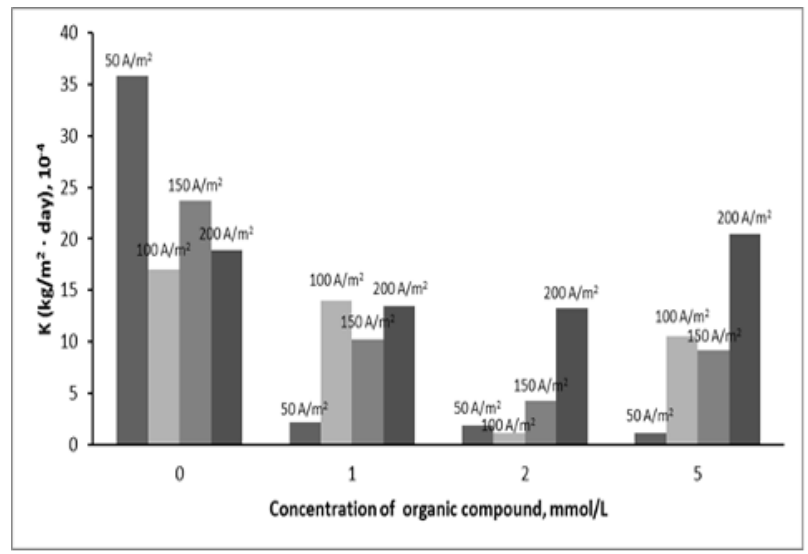

Fig. 3. Rate of SRB-initiated corrosion after eight days of exposure of steel samples with zinc coating deposited in the presence of $\mathrm{OC}$ at different current densities.

An increase in concentration of the SRB culture (that is, with higher numbers of SRB) altered the electrode potential value, medium $\mathrm{pH}$, number of bacterial cells and concentration of biogenic hydrogen sulphide in the medium. At the same time, when organic matters with assumed biocidal activity were embedded in the medium, the values of all the variables that were measured significantly differed from those of the control series.

The first measurement of redox potential, Eh, was performed immediately after the steel was plated with zinc containing the $\mathrm{OC}$ with retarding and biocidal activity-within the 48 hours required for SRB to develop in the presence of random (uncovered) iron plates. Twenty-four hours after exposure, all samples plated with the OC dramatically increased their electrode potential. The redox potential $\mathrm{Eh}$ of the corrosive medium changed with accumulation of $\mathrm{H}_{2} \mathrm{~S}$ to more positive values during the first few days more slowly and then shifted in a positive direction very rapidly, at reaction rates ranging from-334 to $-351 \mathrm{mV}$ (Fig. 4).

Changes in the $\mathrm{pH}$ level of the corrosive medium containing SRB were due to the release of hydrogen sulphide, as their main metabolite together with some other metabolites. The acidity of the corrosive environment was measured immediately after dipping the steel samples coated with zinc, obtained by electrodeposition from the electrolyte with the OC. Introduction of the samples with $\mathrm{Zn}$ coating obtained from the electrolyte with the $\mathrm{OC}$ into the corrosive medium led to the slightly more acidic $\mathrm{pH}$ compared with values obtained with the control series. The changes in $\mathrm{pH}$ decreased with decreasing current density of $\mathrm{Zn}$ deposition from the electrolyte to the input of organic substances, which can be explained by the lower rate of the anode corrosion process of $\mathrm{Zn}$ deposited closer to equilibrium conditions (i.e., with lower internal stresses).

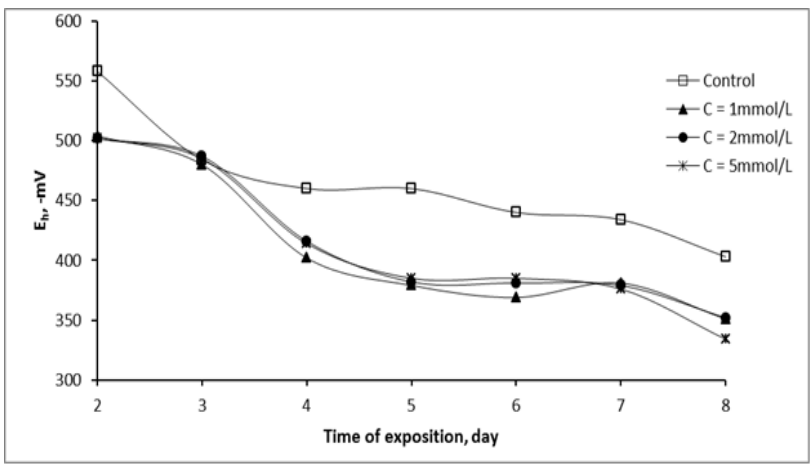

Fig. 4. Eh of system during exposure of steel samples with zinc coating deposited (current density, $50 \mathrm{~A} / \mathrm{m} 2$ ) in the presence of $\mathrm{OC}$ at different concentrations.

The $\mathrm{pH}$ of the medium decreased from 6.2 to 7.18 during exposure (Fig. 5). The improvement in the resistance of mild steel to corrosion was caused by the use of organic substances as additives to the electrolyte for $\mathrm{Zn}$ deposition. The $\mathrm{pH}$ values of the corrosive medium in the control series for four days of the experiment changed toward more acidic values of up to 6.23. Hydrogen sulphide is toxic, having a strong effect on the medium through molecular action, and this creates conditions unfavorable for bacterial growth. After four days of exposure, a uniform increase in $\mathrm{pH}$ values was observed. This was due to corrosion processes on the metal surfaces being accompanied by significant changes in $\mathrm{pH}$, because hydrolysis of the primary corrosion products reduces the $\mathrm{pH}$ in some sections of the anode metal surface. Similarly, at the cathodic sites, depolarisation by $\mathrm{H}_{3} \mathrm{O}^{+}$or $\mathrm{H}_{2} \mathrm{O}$ molecules represents alkalinisation of the corrosive environment.

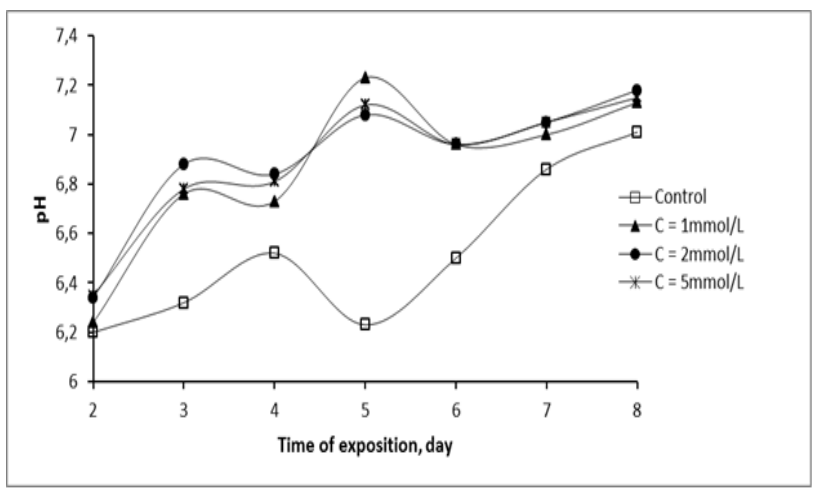

Fig. 5. pH of medium containing SRB during exposure of steel samples with zinc coating deposited (current density, $50 \mathrm{~A} / \mathrm{m}^{2}$ ) in the presence of $\mathrm{OC}$ at different concentrations.

After 24 hours of exposure of the samples coated in electrolyte with the OC, the electrode potential shifted toward more positive values (from-780 to -746 to -711 $\mathrm{mV}$ ) (Fig. 6). 


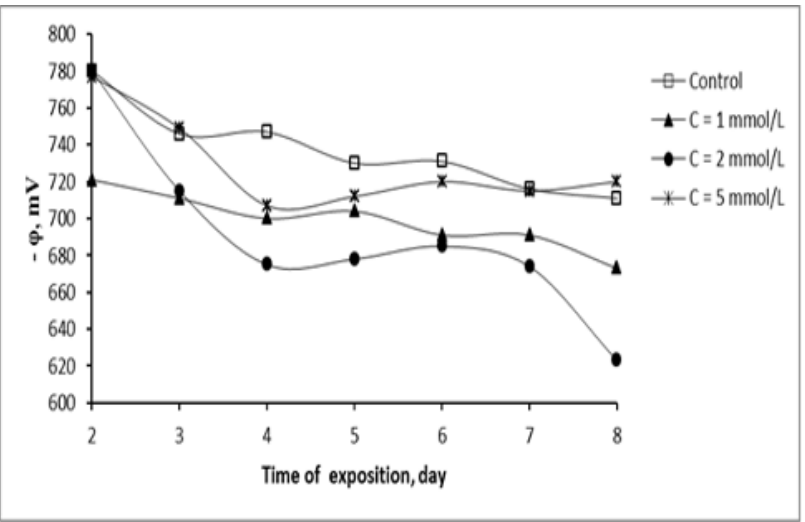

Fig. 6. Electrode potential of steel with $\mathrm{Zn}$ coating deposited (current density, $50 \mathrm{~A} / \mathrm{m} 2$ ) in the presence of MIT at different concentrations.

\section{Conclusions}

This study found that OC molecules adsorbed on the surface of zinc coatings retarded corrosion. This was caused by their becoming embedded in the metabolic chain of microorganisms, which slowed down their vital activity. The $\mathrm{OC}$ at the concentration of $2 \mathrm{mmol} / \mathrm{L}$ exhibited the most effective biocidal and corrosionretarding impact on steel with $\mathrm{Zn}$ coating in a metalsalted water medium containing SRB. A progressive reduction in the $\mathrm{S}^{2}$ concentration in the medium, where steel with $\mathrm{Zn}$ coating was obtained from the electrolyte with the $\mathrm{OC}$ and corroded, as a result of the retardation of metabolic processes in SRB cells, was established, as were redox potential changes. The influence of the examined OC embedded in a zinc-plating electrolyte on the acid- base properties of the corrosive medium was also considered.

\section{References}

1. A. P. Suponina, L. G. Kolzunova and M. A. Karpenko, Russian journal of applied chemistry, 79 (2006), pp. 924-929

2. E. Ilhan-Sungura, N. Canseverb, A. Cotuka, Corrosion Science, 49 (2007), pp. 1097-1109

3. X.G. Zhang Corrosion and electrochemistry of zinc Plenum press, New York and London (1996)

4. J.R.Postgate, L.L.Campbell, Bacteriol. reviews American Society for Microbiology, 30 (1966), pp. 732-738

5. R.E.Tatnall, Materials Performance, 8 (1981), pp. 32-36

6. A.K. Lee, M.G. Buehler, D.K. Newman, Corros. Sci. 48, 1 (2006), pp. 165-178

7. D. Çetin, S. Bilgiç, S. Dönmez, G. Dönmez, Mater. Corros. 58, 11 (2007), pp. 841-847

8. T.S. Rao, T.N. Sairam, B. Viswanathan, K.V.K. Nair Corros. Sci. 42, 8 (2000), pp. 1417-1431

9. P. Angell, K. Urbanic, Corros. Sci. 42, 8 (2000), pp. 897-912
10. D. Çetin, M.L. Aksu, Corros. Sci., 51 (2009), pp. 1584-1588

11. E. Ilhan-Sungur, A. Çotuk, Corros Sci., 52 (2010), pp. 161-171

12. B-Y. Chen1, V. Utgikara, S. Harmona, H. Tabaka, D. Bishopa, R. Govindb, International Biodeterioration \& Biodegradation, 46 (2000), pp.11-18 